\title{
Robert Walsers erster Vertoner: James Simon
}

\author{
Spurensuche
}

1912 hat der Berliner Komponist James Simon Robert Walser entdeckt und vertont. Ob er Robert Walser, der damals ebenfalls in Berlin lebte, persönlich gekannt hat, lässt sich bis heute nicht nachweisen. James Simon wurde 1944 in Auschwitz ermordet. Von seinem Schaffen und seinem tragischen Leben sind nur Bruchstücke erhalten und aufgearbeitet. Sie werden im Folgenden zu einem fragmentarischen Lebensbild zusammengetragen.

\subsection{Einleitung}

Als Robert Walser 1933 gegen seinen Willen in die Heil- und Pflegeanstalt Herisau überführt wurde und seine schriftstellerische Tätigkeit beendete, hatte nach heutigem Kenntnisstand erst ein einziger Komponist zwei Gedichte von ihm vertont: der Berliner Musikwissenschaftler, Musikkritiker, Komponist und Pianist James Simon (1880-1944).

Es ist bedauerlich, dass es keine weiteren Vertonungen aus dieser Zeit gibt, denn die Komponistinnen und Komponisten aus Walsers Generation interessierten sich für literarische Neuerungen, und zentrale Kompositionen entstanden in direkter Auseinandersetzung mit den literarischen Strömungen der Moderne. Die avancierten literarischen Vorlagen steigerten oft noch die innovativen Impulse der Musik, so zum Beispiel bei Arnold Schönbergs Vertonung von Gedichten Stefan Georges oder Alban Bergs Auseinandersetzungen mit Peter Altenberg und Frank Wedekind. Auch konservativere Komponistinnen und Komponisten beschäftigten sich intensiv mit den literarischen Zeitgenossen: Alma Mahler mit Richard Dehmel, Othmar Schoeck mit Hermann Hesse oder Paul Hindemith mit Rainer Maria Rilke. Vor diesem Hintergrund erstaunt es, dass nur einer - der Berliner James Simon die Musikalität von Walsers Sprache erkannte.

Simon selbst ist heute nahezu unbekannt; auch im Zuge der zahlreichen Forschungsprojekte zur verfemten Musik wurde er nicht neu entdeckt. ${ }^{1}$ Simon

1 Ich bin auf den Komponisten über einen auffälligen Eintrag auf einer Liste gestoßen, die mir dankenswerterweise Ernst Meier von der schweizerischen Urheberrechtsgesellschaft SUISA zum Stichwort Robert Walser zusammenstellte: Da steht »Simon Simrock?« Über eine 
zählt zu den zahlreichen Opfern des Nationalsozialismus, die in Auschwitz ermordet wurden und nach 1945 nicht etwa rehabiliert worden, sondern erst recht in Vergessenheit geraten sind. Angesichts dieses Schicksals seien Leben und Werk von James Simon, zu dem noch keine Studien existieren und der hier erstmals in einer deutschen Publikation behandelt wird, ausführlicher dargestellt, soweit das die relativ spärlich erhaltenen Zeugnisse und Dokumente erlauben. Die folgenden biografischen Skizzen stützen sich in erster Linie auf die Ausführungen des Gründungsdirektors der Terezin Musical Memorial Foundation, David Bloch, ${ }^{2}$ auf Briefdokumente in der Musikabteilung der Staatsbibliothek zu Berlin, auf den Nachlass von Toni Appelbaum und die jüngste Dokumentation von Philip Silver und Carine Alders. ${ }^{3}$

Die erste biografische Notiz zu James Simon stammt von diesem selbst und findet sich am Schluss seiner Dissertation über den Komponisten, Kapellmeister und Weltenbummler Abbé Vogler:

Internetrecherche fand ich dann die Homepage von Claude Torres (Torres: James Simon). Dieser brachte mich mit der israelischen Sängerin Hannie Ricardo zusammen, die Simons erste Walser-Vertonung mit Allen Sternfield aufgeführt hat (vgl. Ricardo: Gebet.James Simon), und zwar im Rahmen eines Gedenkkonzerts für den amerikanisch-israelischen Musikwissenschaftler und Gründungsdirektor der Terezin Musical Memorial Foundation, David Bloch (1939-2010), auf dessen biografische Notizen zu James Simon sie mich aufmerksam machte (vgl. Bloch: James Simon). Ein Teil des unpublizierten Nachlasses von James Simon befindet sich im Leo Baeck Institute, New York. Es handelt sich dabei um Werke, die nach 1931 entstanden und fast durchwegs seiner Geliebten Toni Appelbaum gewidmet sind. Ein Manuskriptbestand befindet sich in der British Library: Simon Music Manscripts Add MS 62117-62120. Samuel Weibel von der Universitätsbibliothek Bern entdeckte für mich im alten Katalog der Preußischen Staatsbibliothek einen Großteil der publizierten Kompositionen von James Simon. Philip Silver und Carine Alders haben innerhalb des niederländischen Online-Projekts »Forbidden Music Regained «, das sich um die Dokumentation verfemter Komponistinnen und Komponisten während der nationalsozialistischen Besetzung Hollands bemüht, Simons Aufenthalt in Amsterdam aufgearbeitet (vgl. Silver/Alders: James Simon). Ich danke der Universal-Edition Wien und dem Politischen Archiv des Auswärtigen Amtes Berlin für die Unterstützung bei den Recherchen. Dank gebührt auch Walter Labhart, der mich auf Simons Pseudonym Peter Potter aufmerksam machte und meine Recherchen mit seiner Dokumentationsbibliothek unterstützte. Wieviele Werke von Simon verschollen sind, zeigt schließlich ein Artikel zu seinem fünfzigsten Geburtstag, in dem große - u. a. von Hermann Scherchen aufgeführte - Orchesterwerke und vier Streichquartette erwähnt sind. Vgl. Ehrens: James Simon 50 Jahre!, S. 1114.

2 Vgl. Bloch:James Simon.

3 Vgl. Silver/Alders:James Simon. 
Ich, James Simon, bin am 29. September 1880 zu Berlin als ältester Sohn eines Bankiers geboren und gehöre der jüdischen Religionsgemeinschaft an. Ich besuchte das Friedrichs-Werdersche Gymnasium zu Berlin, erlangte dort im Herbst 1898 das Zeugnis der Reife und bezog dann die Universität Berlin. Hier hörte ich 7 Semester Vorlesungen bei den Herren: Friedlaender, Fleischer, Paulsen, Dessoir, Dilthey, Simmel, Erich Schmidt, Geiger, R. M. Meyer, Sternfeld, Wilamowitz-Moellendorf. An seinen Übungen gestattete mir Herr Prof. Friedlaender teilzunehmen. Von Ostern 1899 bis Ostern 1902 gehörte ich außerdem der Kgl. Akad. Hochschule für Musik in Berlin an; das folgende Sommersemester studierte ich in Bonn. Michaelis 1903 bezog ich die Universität München. Hier hörte ich Vorlesungen bei den Herren Kroyer, Lipps, Muncker, Paul, Sandberger. ${ }^{4}$

Simon präsentiert hier ein beachtliches universitäres Adressbuch, das wichtigste Namen der deutschen Wissenschaftselite am Ende des 19. Jahrhunderts umfasst ${ }^{5}$ und seine breiten Interessen zeigt. Er besuchte neben musikhistorischen auch philologische, historische, philosophische, psychologische und literaturhistorische Vorlesungen. Auffällig ist die Nennung des Literaturwissenschaftlers Ludwig Geiger in München, der wegen seiner jüdischen Herkunft an den Rand des universitären Betriebs gedrängt wurde und nur ein Extraordinariat erhielt.

Simons Karriere als Musikwissenschaftler begann schon früh mit einem wichtigen Auftrag: Er durfte bereits mit 26 Jahren in der renommierten und von Richard Strauss patronierten populärwissenschaftlichen Reihe Musik eine selbstständige Schrift zu Faust in der Musik als Band 21 von insgesamt 52 Bänden publizieren. Die Verfasser dieser Reihe waren weniger die universitären Musikwissenschaftler als vielmehr wichtige Musikkritiker der damaligen Zeit, darunter auch umstrittene wie Oskar Bie und Werner Suhr, die pointiert für die zeitgenössische Kunst und den zeitgenössischen Tanz einstanden. James Simon befindet sich da also in guter Gesellschaft. Seine Schrift ist sehr gewissenhaft und mit jenem akribischen Forschergeist verfasst, der schon seine Dissertation über Abbé Vogler auszeichnet. Er sammelt und

4 Simon: Abt Voglers kompositorisches Wirken, S. 64.

5 Max Dessoir (1867-1947), Philosoph und Psychologe; Wilhelm Dilthey (1833-1911), Theologe und Philosoph; Oskar Fleischer (1856-1933), Musikwissenschaftler; Ludwig Friedländer (1824-1909), Altphilologe und Kulturhistoriker; Ludwig Geiger (1848-1919), Literatur- und Kulturhistoriker; Theodor Kroyer (1873-1945), Musikwissenschaftler; Theodor Lipps (18511914), Philosoph und Psychologe; Richard Moritz Meyer (186o-1914), Germanist; Franz Muncker (1855-1926), Germanist; Hermann Paul (1846-1921), Sprachwissenschaftler; Friedrich Paulsen (1846-19o8), Pädagoge und Philosoph; Adolf Wilhelm Sandberger (1864-1943), Musikwissenschaftler und Komponist; Erich Schmidt (1853-1913), Germanist; Georg Simmel (1858-1918), Soziologe und Philosoph; Richard Sternfeld (1858-1926), Musikwissenschaftler und Historiker; Ulrich von Wilamowitz-Moellendorff (1848-1931), Philologe. 
kommentiert viele musikalische Auseinandersetzungen mit dem Faust-Stoff, und man staunt heute über das immense bibliografisch-lexikalische Wissen, das zu Beginn des 20. Jahrhunderts bereits zur Verfügung stand. Simon erkennt die Bedeutung des Don-Juan-Stoffs - und damit auch Mozarts - für die Verbreitung des Faust-Stoffs im 19. Jahrhundert und stellt sich mutig den Vorurteilen zu den Faust-Versionen von Hector Berlioz und Robert Schumann entgegen, die damals noch als diabolisch-exaltiert bzw. als schwaches Alterswerk galten.

James Simon bemühte sich unmittelbar nach Abschluss der Dissertation um Kontakte zum Komponisten Max Bruch (1838-1920) und zum Pianisten und Komponisten Conrad Ansorge (1862-1930), um Kompositions- bzw. Klavierstudien zu betreiben. Die in Berlin erhaltenen Briefe von Max Bruch an Simon zeigen einen unverkrampften und von Ironie geprägten Umgang des 1905 bereits 67 Jahre alten Lehrers mit seinem Studenten:

\section{M. l. Simon,}

Ich würde mich freuen Sie übermorgen Freitag d. 14., um 12 Uhr bei mir zu sehen (eventuell auch »haben«). Frdl. Ihr Dr. M. Bruch. ${ }^{6}$

Beim Vereinbaren eines späteren Termins schildert Bruch offen sein Leben zwischen Mittagsruhe und einem Rendezvous mit einer Dame der höheren Gesellschaft:
M. l. Simon
In der Mittagsstunde ist mir jetzt fast unmöglich, einen Gedanken zu fassen. Freitag Nachmittag zwischen 4-7 bin ich bei Etelka Gerster; aber Sonnabend d. 3. Juni um $5^{1 / 2}$ würde ich Ihnen zur Verfügung stehen, da ich die Herzogin Cecilia nicht abholen werde, aber Sie [würden dann $]^{7}$ wohl den Einzug haben wollen[. $]^{8}$

Als James Simon 1905 den Kompositionsunterricht bei Max Bruch besucht, gilt dieser schon als hoffnungslos veralteter Komponist und Vertreter einer

6 Bruch: Postkarte vom 12.10.1904.

7 Lesart unsicher.

8 Bruch: Postkarte vom 01.05.1905. Die in der Postkarte erwähnte Etelka Gerster (1855-1920) war eine ungarische Sopranistin, die nach einer internationalen Karriere 1889 in Berlin eine erfolgreiche Gesangsschule eröffnete und leitete. Der Hinweis auf den Einzug der Herzogin Cecilia ist ein kritisch-ironischer Seitenhieb auf die pompösen Feierlichkeiten zur Hochzeit des deutschen Kronprinzen Friedrich Wilhelm mit der Herzogin Cecilie von Mecklenburg am 6. Juni 1905, der drei Tage währende Festivitäten unterschiedlichster Art vorausgingen. 
vergangenen Zeit. Bruch komponierte in der Nachfolge von Felix Mendelssohn und in der Tradition von Johannes Brahms und lehnte alle Einflüsse der neudeutschen Schule ab, also Franz Liszt, Richard Wagner sowie später Richard Strauss und Max Reger. Conrad Ansorge dagegen, bei dem Simon sich zum Konzertpianisten ausbilden ließ, kam aus eben dieser Schule, denn er war einer der letzten Schüler von Franz Liszt. Allerdings spielte Ansorge auch das Klavierrepertoire des 18. und frühen 19. Jahrhunderts und galt als ein wichtiger Mozart- und Schubert-Interpret. Sein feines und differenziertes Rubato und im Falle von Mozart und Schubert erstaunlich klassizistisches Klavierspiel ist sowohl auf frühen Welte-Mignon- als auch auf Schallplattenaufnahmen dokumentiert. ${ }^{9}$

Mit diesen beiden gegensätzlichen Lehrern setzte Simon fort, was schon seine universitären Studien ausgezeichnet hatte: Er suchte sich eher konservative Lehrer mit breitem Horizont. Einzig zur Moderne fand er mit diesen Lehrerfiguren keinen Kontakt.

Schon in jungen Jahren hatte James Simon auch als Musikkritiker gearbeitet. Er finanzierte seinen Lebensunterhalt mit diversen musikalischen Tätigkeiten, die Komponieren, Unterrichten, Konzertieren als Pianist und Kommentieren von Musik umfassten. Er schaffte es jedoch nicht, in einer der vielen Domänen in die erste Reihe zu gelangen: Seine spätromantische Musiksprache passte immer weniger in die Zeit der Moderne, als Pianist war er meist nur Begleiter, und die sporadisch gegebenen Solorezitals führten zu keinem durchschlagenden Erfolg.

James Simon muss eine kultivierte und eher zurückhaltende Persönlichkeit gewesen sein. In den Dokumenten des Baeck Institute findet sich nur ein etwas großspurig aufgemachter Werbeflyer in deutscher und englischer Sprache, mit dem er sich auf der Flucht wohl ins Gespräch zu bringen versuchte. ${ }^{10}$ Auch im mutmaßlich einzigen publizierten Nachruf auf Simon wird dessen Kultiviertheit besonders betont:

Besonders aufschlussreich ist Conrad Ansorges differenzierte Rubato-Technik bei seinen Schubert-Einspielungen: Auf Welte-Mignon Impromptu c-Moll op. 9o Nr. 1, D 899 (Rolle Nr. 287, Aufnahme: 1905); auf Hupfeld (Phonola) Sonate für Klavier B-Dur D 96o, 1. Satz: Molto moderato (Rolle Nr. 5039o a/b, 12643); auf Philipps (Duca) F.S./Franz Liszt: Soirée de Vienne. Valses-caprices d'après Schubert Nr. 6. a-Moll R 252/S 427 (Rolle Nr. 776); auf Schallplatte Moment musical f-Moll op. 94 Nr. 3, D 780 (Parlophone E 10986/Parlophone France 570o9, Odeon O-7814, American Decca 25357, LP Opal 824/5). 
Ungewöhnlich anziehend wie als Musiker war Simon auch als menschliche Erscheinung: Durch seine hohe geistige und seelische Kultur wurde jedes Zusammensein, jedes Gespräch mit ihm zu einer seltenen Bereicherung. Seine vielseitige und tiefe Bildung liess ihn auch über die Hauptgebiete seiner Kunst: Komposition und Pianistik, weit hinauswachsen."

\subsection{Ein Leben am Rande}

Am 1. Mai 1907 heiratet Simon Anna Levy (1885-1975); sie bekommen zwei Söhne. Die vierköpfige Familie wird während des Nationalsozialismus das tragische Schicksal des deutschen Judentums erfahren. Die Söhne gehen sehr unterschiedliche Wege: Jörn Martin Simon (1910-1937) flieht in die Sowjetunion und gilt seit den stalinistischen Schauprozessen 1937 als verschollen. Den jüngeren Sohn Ulrich Ernst Simon (1913-1997) schicken die Eltern 1933 nach London; er konvertiert dort zum christlichen Glauben und wird später ein namhafter anglikanischer Theologe.

Nach seiner Ausbildung bei Max Bruch beginnt James Simon ein reiches kompositorisches Schaffen, das sich vorerst auf Lieder konzentriert. Er wird während des Ersten Weltkriegs nicht eingezogen und kann weiterhin am Klindworth-Scharwenka-Konservatorium in Berlin unterrichten. 1914 beteiligt er sich mit Vier Kriegslieder op. 11 am Aufruf an die deutschen Komponisten, Kriegslieder zur Stärkung des Wehrwillens zu komponieren. Simon wählte Texte aus, welche auch die Schrecken des Kriegs zeigen und die Waisen und Witwen thematisieren (Kriegsspruch von Alfons Petzold) oder wo ein Angriff wegen eines Gebets verzögert wird (Vor der Schlacht von Kurt Münzer). Einzig das letzte Lied mit einem Text von Gerhart Hauptmann ist platt nationalistisch (Reiterlied). Erstaunlich istallerdings, dass Simon einen als >Volkslied < getarnten Text von Sándor Friedrich Rosenfeld (1872-1945), der unter dem Pseudonym Roda Roda publizierte und auftrat, in seine Kriegslieder schmuggeln konnte. Er ist an Sarkasmus kaum zu überbieten!

Ein Befehl kam an die Bauern: Nehmt den Spaten, kommt begraben, kommt begraben die Soldaten.

Einen Klafter tief und zwanzig Klafter Länge, dritt'halb Ellen breit, dann liegen sie nicht enge.

Fleissig haben wir die Grube ausgegraben, die Gemeinen unten, Korporale oben, seitwärts viere, in der Mitten viere, 
überquer die Herren Offiziere.

Sauber haben wir's mit Kalk begossen, ist noch manchem aus der Brust das Blut geflossen.

Drauf den Obersten in einer Truhe -

Jetzt haben die Soldaten ihre Ruhe. ${ }^{12}$

Die deutsche Zensurbehörde muss geschlafen haben, als sie diesen bösen und von Simon listig harmlos vertonten Text durchwinkte. 1915 schreibt Simon mit dem Kriegsflugblatt Nr. 23/24 Eine Glocke läutet im Grund nochmals drei Kriegslieder auf Texte von Richard Dehmel, Hermann Hesse und Oskar Wöhrle, die alle drei nur noch mit der Trauer und dem Andenken der Toten beschäftigt sind.

Bei den durch Briefquellen dokumentierten Kontakten von Simon bekommt man den Eindruck, dass er zuweilen nur als Lückenbüsser angefragt wurde zum Beispiel vom renommierten Münchner Kammer- und Opernsänger Paul Bender (1875-1947), dem Simon auch beim Einrichten der Klaviersätze behilflich war. Wenn der berühmte Bass einen Klavierbegleiter in der Provinz brauchte, fragte er James Simon: »Teilen Sie mir bitte baldigst mit, ob Sie mich eventuell in Liegnitz am 29 April begleiten könnten und welches Honorar incl. Reise - Sie beanspruchen würden. ${ }^{13}$ Wenn Bender allerdings in Berlin sang, wurde er von namhafteren Pianisten begleitet.

\subsection{Auseinandersetzung mit Ferruccio Busoni}

Während des Ersten Weltkriegs knüpfte Simon Kontakt zum damals in Zürich lebenden Komponisten Ferruccio Busoni (1866-1924); er gratulierte ihm zum

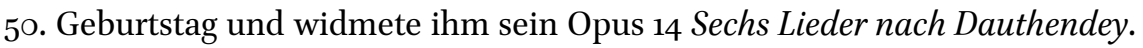
Nach dem Krieg kam es jedoch zu einer Auseinandersetzung zwischen Busoni und Simon. Auslöser war eine Kritik von Simon in der interdisziplinären Kulturzeitschrift Feuer, die verschiedene Kunstsparten behandelte und vom Musikwissenschaftler und späteren Filmmusik-Pionier Guido Bagier (18881967) herausgegeben wurde. Simons Mitarbeit als Musikkritiker in Feuer beschränkte sich vor allem auf die Rezension von Büchern, weil die großen musikalischen Themen vom Herausgeber Guido Bagier selber übernommen

\footnotetext{
12 Zit. nach Simon: Vier Kriegslieder, Nr. 3.

13 Bender: Telegramm vom 3.Januar 1921. Liegniz, Niederschlesien, liegt heute auf polnischem Staatsgebiet und heißt Legnica.
} 
wurden. Zum Konflikt kam es aber ausgerechnet beim gewichtigen Auftrag, ${ }^{14}$ die Kritik der Berliner Aufführung von Ferruccio Busonis Kurzopern Turandot und Arlecchino zu schreiben. Simon erwähnt in seiner gedanklich und sprachlich hervorragenden Werk- und Aufführungskritik die »intellektuellartistischen Triebe« des Komponisten:

Wir sind ja in der Heimat Donizettis, der sinnreich zitiert und köstlich parodiert wird. Hier besonders fällt die kluge Sparsamkeit in der Orchesterbehandlung auf; man beachte nur die Auslese der Instrumente: Flöte und Celesta über Trompeten und Posaune! Weshalb die letzte erobernde Wirkung beim Publikum und dem größten Teil der Presse nicht ausgelöst wurde? Offenbar, weil hier intellektuell-artistische Triebe das Elementar-Gefühlsmäßige zurückdrängen Herzensergüsse wie »Die Welt ist offen ...« sind eine Seltenheit in diesem eher geist- als gemütvollen Werke - und weil feingeistige Grazie immer nur von wenigen gewürdigt wird. ${ }^{15}$

Ferruccio Busoni, der eben an der Musikhochschule Berlin eine Meisterklasse für Komposition übernommen hat, protestiert - wohl auch weil Simon so unverblümt die Erfolglosigkeit der Kurzopern zu erwähnen wagt - und schreibt dem Komponisten am 30. August 1921:

Lieber und sehr geschätzter Dr. James Simon,

Sie beschäftigen sich liebe- und verständnisvoll mit mir und meinen Sachen, wofür ich Ihnen von Herzen - zunächst - danken will und muss. - Ich hoffte Sie bei mir zu sehen. Leider scheint ein Missverständnis Sie davon abzuhalten.

Heute erhalte ich eine Nummer des »Feuer«, worin Sie mir wiederum die Ehre erweisen, sich mit mir abzugeben. Als ich der ersten Vorstellung des »Arlecchino « beiwohnte, berührte Schillings meinen Arm und sagte: »Geist und - Können.« Worauf ich antwortete: »Ja, aber das Gefühl fehlt. So ein bischen [sic] >Holder Abendstern` wäre herbeizuwünschen.«Wir wollen nicht spalten. Aber ich muss mich dagegen wehren, dass ein Werk, das einzig auf Gefühl gestellt ist, (womit ich weder Sentimentalität, noch Liebesschwärmerei, noch Brutalität meinen kann!) so verkannt wird. Es drückt in Allem nur Mitleid mit den Menschen aus, und die innigste Teilnahme an ihren Irrungen. Was ist mein grosses unerreichtes und unerreichbares Muster »Don Quijote« anders? - Oder, ist das wirklich Ihre Empfindung, dass »Schwelgen« »Gefühl« bedeutet? - Dazu sind Sie selbst zu intelligent und kritisch und begabt. - Ich bitte Sie, diesen Protest nicht anders aufzufassen, als wie ein Zeichen meines Vertrauens zu Ihnen, dem ich herzlich ergeben verbleibe.

Ihr F. Busoni ${ }^{16}$

14 Schon ein halbes Jahr zuvor hatte Simon einen längeren Aufsatz zu Ferruccio Busoni in Feuer publiziert. Vgl. Simon: Busoni.

15 Simon: Busonis Opern, S. 653 .

16 Busoni: Brief vom 30.08.1921. 
James Simon antwortet innert Wochenfrist am 6. September 1921. Er gibt sich zwar unterwürfig, nimmt letztlich aber nichts von seiner Kritik des Intellektualistischen zurück, sondern bringt als negative Beispiele für sentimentale Gefühligkeit neben Tschaikowsky die von Busoni erwähnte Arie »O du mein holder Abendstern« des Wolfram aus Wagners Tannhäuser ins Spiel. Interessant ist auch die Bemerkung zum schlechten Geschmack des großen Publikums, mit der sich der spätere Freund der sozialistischen Bewegung hier noch als Vertreter der Kulturaristokratie gibt, was aber auch dem Briefadressaten geschuldet sein könnte:

Sehr verehrter Herr Dr Busoni,

Ihre geschätzten Zeilen vom 30. August gingen von der Konzertdirektion Wolff noch an meine Reiseadresse und gelangten erst gestern abend zu mir - womit Sie die Verzögerung meiner Antwort entschuldigen mögen. Für Ihren Protest, den ich ja nur auf den Schluss meiner Harlekin-Besprechung zu beziehen brauche, bin ich Ihnen sehr dankbar!, denn abgesehen davon, dass ich in ihm keinen Angriff, sondern ein Zeichen von Achtung und Interesse sehe, hat er allerlei fruchtbare Gedanken in mir aufgewühlt. Vielleicht überschätzte ich das tendenziöse Moment Ihres Werkes und wurde daher dem Gefühlsquell, aus dem es entspringt, nicht in genügendem Masse gerecht. Ich wollte mit meiner Schlussbemerkung auch mehr den psychologischen Erklärungsgrund dafür angeben, weshalb das grosse Publikum (dessen Geschmack und Bewertung doch recht diskutabel sind) nicht unmittelbar gepackt wurde. Obwohl ich mich nicht zu letzterem rechne, wurden mir Mitleid und Rührung zunächst auf indirektem Wege erregt, dieses »Schade um die Menschen!« Wahrscheinlich wird es mir bei wiederholtem Hören gelingen, das Symbolische gleich mitzuerfahren. Sie legen eben Ihr Gefühl - wenn ich so sagen darf - nicht auf den Präsentierteller wie etwa Tschaikowski oder wie Wolfram in der von Ihnen zitierten Situation, da er den Abenstern anhimmelt.

Es wäre mir eine besondere Freude noch persönlich mit Ihnen über dieses Thema sprechen zu dürfen, und so benutze ich diesen Anlass gern Sie wieder einmal aufzusuchen. Hätten Sie im September etwas Zeit für mich?

Mit grösster Hochachtung

Ihr Ihnen treu ergebener

James Simon ${ }^{17}$

\subsection{Frau im Stein}

Nur wenig später wagte James Simon selber den Schritt zur Oper: Frau im Stein sollte zu seinem Durchbruch als Komponist führen. Simon gelang es, den damals führenden Verlag im Bereich Neuer Musik, die Universal-Edition

17 Simon: Brief vom o6.og.1921. 
Wien-New York, die Schönberg, Berg und Webern edierte, für sein Vorhaben zu gewinnen. Ein Erfolg wurde die Oper nicht; gemäß David Bloch wurde sie nur ein einziges Mal gespielt. ${ }^{18}$ Das Werk basiert auf dem gleichnamigen expressionistischen Drama von Rolf Lauckner (1887-1954).

Die Handlung der Oper ist eine ins sexuell Triebhafte verschobene Darstellung des Ariadne-Mythos.

Theseus bringt den Minotaurus in dieser Bearbeitung des Mythos nur aus Lüsternheit um, weil ihn Ariadnes Körper und vor allem ihre Füsse aufreizen. Nachdem er Minotaurus erschlagen hat, scheint er von dessen Stierdasein affiziert zu werden: Auf der Insel Naxos will Theseus über Ariadne herfallen. Diese wird wegen des Mordes an ihrem Halbbruder Minotaurus plötzlich von Gewissensbissen verfolgt und verweigert sich Theseus. Ihm kommt in dieser Situation die sexuell freizügige Schwester Phädra gerade recht. Sie liebt die »heissen Blicke $\ll^{19}$ von Theseus und segelt mit ihm von der Insel weg. Die zurückgelassene Ariadne gelobt sich, auf einem Felsen auf Theseus zu warten. In ihrer Klage wird sie vom Felsen erlöst und zur >Frau im Stein ‘.

Zwar geht Simon bei der Vertonung dieses expressionistischen Wälzers über die gemäßigte romantische Musiksprache hinaus, die er bei Max Bruch gelernt hat, aber er will doch nicht in den expressionistischen Ton verfallen, den Hindemith oder Schönberg bei vergleichbaren Opernstoffen gesucht haben. Simon bleibt seiner romantischen Herkunft treu. Unglücklicherweise ging die Uraufführung der Oper am Sonntag, 1. März 1925 ob des plötzlichen Todes von Reichspräsident Friedrich Ebert am Vortag unter. Aufgrund der Kritik in den Signalen muss zudem vor allem der Librettist Rolf Lauckner bei einer Morgeneinführung mit der Ankündigung einer neuen Form des Gesamtkunstwerks

18 Ein Uraufführungsdatum gibt David Bloch nicht an, und auch auf der entsprechenden Karteikarte der Universal-Edition ist kein Aufführungsdatum verzeichnet. Die Oper wurde aber am 1. März 1925 am Württembergischen Landestheater Stuttgart uraufgeführt. Regie führte Otto Erhardt, die musikalische Leitung oblag Carl Leonhardt. Die Kartei in der Universal-Edition verzeichnet noch einen Versand der Partitur an Simon am 15. April 1927 und eine Ausleihe des Aufführungsmaterials nach Berlin vom 29. Oktober bis zum 20. November 1930, was auf weitere Aufführungspläne hinweist, die aber nicht belegt sind. Dieselbe Karteikarte enthält auch die Bemerkung, dass am 5. Mai 1944 der Klavierauszug der Oper vernichtet wurde, wahrscheinlich im Rahmen der nationalsozialistischen Aussonderungen jüdischer Komponisten. Vgl. E-Mail von Katja Kaiser, Historical Archive der Universal-Edition, an den Autor vom 05.07.2016. Die Besetzung der Oper gemäß Karteikarte: 3/3(Englischhorn)/3/2 - 4/3/3/1 - Pauke, Schlagzeug, 2 Harfen, 1 Celesta $-6 / 5 / 4 / 3 / 3$. Hoher Bariton (Theseus), Sopran (Ariadne), Sopran (Phädra), Bassbariton (Priester), 3 Chöre.

Simon: Frau im Stein [Klavierauszug], S. 96f. (III. Akt, Takte 196-206). 
Kunstansprüche angekündigt haben, die schließlich auf die Komposition zurückfielen:

»Viel, sogar sehr viel Wagnerisches steht neben Eigenem, ohne daß Wagners Motivkunst erreicht wäre. [...] Wenn man von den Absichten und ästhetischen Prinzipien der Verfasser ausgeht, kann man nur sagen, die erstrebte Synthese ist nicht erreicht. Das Werk bedeutet eben nicht den Markstein in der Geschichte der Oper, der es sein will. Es ist guter Durchschnitt. ${ }^{20}$

\subsection{Sozialistische Bewegung und Flucht}

Die zwei letzten in der Staatsbibliothek Berlin erhaltenen Partituren von Simon zeigen, dass er sich in den späten 192oer-Jahren mit Filmmusik - vom schüchternen Komponisten ist ausgerechnet die Stummfilmmusik Angst überliefert - beschäftigte und sich der sozialistischen Bewegung angeschlossen hatte. Beim Hoffmanns Verlag in Berlin, der schwerpunktmäßig sozialistisches Liedgut druckte, erschien der gemischte Chor Freiheit nach Bartolomeo Vanzetti (1888-1927), zusammen mit dem Russischen Rotgardistenmarsch von Jörg Mager (188o-1939), dem Mikrointervall- und Elektronikpionier. Im Gegensatz zu den meisten im Hoffmanns Verlag gedruckten Arbeiterliedern, wie zum Beispiel Gruss an den 1. Mai, Proletariermädchen, Ihr Frauen, aufgewacht!, ${ }^{21}$ fehlen in Simons Gesang die politischen Floskeln:

Freiheit! Kennst du sie? Freiheit, was ist das? Ich weiß nicht! Freiheit! Das Wort klingt in allen Sprachen, und nirgends ist die Freiheit! Du hast sie gesehen? Wo? Auf Erden, wo? Du lügst! Denn Freiheit[,] das wäre das Ende aller Unmenschlichkeit, wäre das Ende aller Grausamkeit, wäre das Ende aller Gehässigkeit, wäre das Ende aller Niedertracht! Freiheit hieße: die Welt ist selig geworden! Freiheit? Freiheit? Ich kenne nur das Wort! ${ }^{22}$

Wie schon bei den zu Beginn des Ersten Weltkriegs komponierten Kriegsliedern ließ sich Simon mit diesem Freiheitslob nicht in platte Propaganda einbinden. In dieser Zeit unterhält er auch Kontakt zum damals in der sozialistischen Bewegung tätigen Komponisten und Musikkritiker Max Butting

20 Stuart: Uraufführung:James Simons »Frau im Stein« in Stuttgart, S. 368.

21 Zit. nach der ausführlichen Verlagswerbung auf der Partitur.

22 Zit. nach der Partitur: Simon: Freiheit. Auf der Titelseite wird als Autor Bartholomé Vanzetti, bei den Noten jedoch Bartolomeo Vanzetti geführt. 
(1888-1976), der nach 1945 - obwohl NSDAP-Mitglied - zu einem wichtigen Musikfunktionär der DDR wurde. ${ }^{23}$

In den 1920er-Jahren erscheint James Simon als Lemma in verschiedenen Musiklexika, am ausführlichsten 1926 im von Alfred Einstein betreuten Das neue Musiklexikon. ${ }^{24}$ Dort findet sich auch der Hinweis, dass Simon von 1907 bis 1919 am Klindworth-Scharwenka-Konservatorium in Berlin als Klavierlehrer unterrichtet hatte. ${ }^{25}$

Ab 1931 bahnte sich eine zunehmend intensive Beziehung zu Toni Appelbaum (alias Apel) an. ${ }^{26}$ Sie war die Schwägerin des Musikwissenschaftlers Willi Apel, mit dessen Bruder Hans sie verheiratet war. Bis ${ }_{1936}$ lebte sie in Berlin, dann emigrierte sie in die USA, wo sie - getrennt von ihrem Mann - in Willi Apels Haus in Belmont, Massachusetts, nahe Cambridge lebte. Toni Appelbaum muss musikalisch und literarisch hochgebildet gewesen sein, denn James Simon übersäte seine Briefe an sie mit musikalischen Zitaten, versteckte in den ihr gewidmeten Kompositionen geheime Botschaften, die er in einem Folgebrief aufschlüsselte; er kopierte ihr auch Stellen aus der Musikgeschichte, die auf seinen und ihren Gemütszustand referierten. Aus den Briefen geht zudem hervor, dass sie sich über deutsche und französische Literatur unterhalten haben. Aufgrund der Dokumentenlage muss Simon fast alle Kompositionen seines letzten Lebensjahrzehnts für Toni Appelbaum geschrieben haben. Es handelt sich dabei vorwiegend um Liebeslieder, die Simon 1933 aus Zürich und ab 1934 aus Amsterdam an Toni Appelbaum sandte. Hier tauchen nun auch Gedichte der >Avantgardisten< auf: Else Lasker-Schüler, Paul Verlaine, Hans Bethge, Stefan George und Friedrich Gundolf, die in den publizierten Liedern der Berliner Zeit noch fehlen. Aus Zürich schickt er 1933 gleich vier Vertonungen des frühen Walser-Förderers Christian Morgenstern nach Berlin, darunter Präludium: »Meiner lieben Toni zur Erinnerung an Sonnentage des Lebens! ${ }^{27}$

23 Am 24. Oktober 1929 schrieb Simon an Max Butting, er würde gerne den Marsch aus dessen Vier Klavierstücken op. 31 an seinem Klavierabend im Beethovensaal am 3. Dezember 1929 spielen. Simon: Brief vom 24.10.1929. Vgl. Brennecke: Das Lebenswerk Max Buttings.

24 Eaglefield-Hull/Einstein: Das neue Musiklexikon, S. 598.

25 Lemmas zu James Simon finden sich auch in Abert: Illustriertes Musiklexikon, S. 436; Frank/Altmann: Kurzgefaßtes Tonkünstler-Lexikon (1926), S. 377; Müller: Deutsches Musiker-Lexikon, S. 1554. Ich danke Walter Labhart für diese Recherchen in seiner Dokumentationsbibliothek.

26 Simon schreibt Toni sowohl in Berlin als auch in den USA immer mit »Appelbaum« an, obwohl die gesamte Familie den Namen auf Apel geändert und Wilhelm Appelbaum sogar seinen Vornamen auf Willi verkürzt hatte.

27 Simon: Präludium. 
Simons sozialistisches Engagement ist wohl der Grund dafür, dass er schon $1933^{28}$ mit seiner Familie aus Deutschland flüchtete. Wie Wladimir Vogel, den er wegen dessen Engagement in der Arbeiterbewegung mit hoher Wahrscheinlichkeit kannte, floh er über Zürich nach Amsterdam. ${ }^{29}$ Wahrscheinlich in dieser Zeit muss sich Simon das Pseudonym >Peter Potter ${ }^{30}$ zugelegt haben, wohl um seine jüdische Herkunft zu verbergen. ${ }^{31}$ Möglich wäre zwar auch, dass Simon sich dieses englisch-modern klingende Alias für wenig repräsentative Werbemusikaufträge zulegte; dies suggeriert eine Notiz des Emigrationsforschers Günter Peter Straschek, der am 15. Oktober 1984 mit Simons Sohn ein Telefongespräch führte: »Prof. Ulrich Ernst S. (London) zufolge mag sein Vater an Kurz- und Reklamefilmen mitgearbeitet haben. ${ }^{32}$ Allerdings taucht im TonFilmführer ${ }^{33}$ von $193^{2}$ der Name von James Simon im Kapitel »Film-Musik-Autoren« ohne >Peter Potter auf. Deshalb handelte es sich vermutlich um einen Tarnnamen, der ihn vor rassischer Verfolgung und Benachteiligung schützen sollte. Das belegt auch die Tatsache, dass die Nationalsozialisten in ihren Lexika dieses Pseudonym enttarnten. Zwar fehlt in der 1935 publizierten ersten denunziatorischen Sammlung der Juden in der Musik von Christa Maria Rock und Hans Brückner dieser Hinweis auf Peter Potter; dafür wird in diesem Buch, in dem nicht-arische Musiker nur noch als »Musikbeflissene« bezeichnet werden, mit der Nennung von Giacomo Meyerbeer auf den rassisch >belasteten< Stammbaum Simons hingewiesen: »Durch

28 David Bloch gibt als Emigrationsdatum den 1. April 1933 und schreibt, dass Simon über Zürich geflohen sei. Gerhard Keiper vom Politischen Archiv des Auswärtigen Amtes Berlin mailte mir freundlicherweise die erhaltene Akte zum Ausbürgerungsvorgang von James Simon. Archivband R 99804 (Referat Deutschland, 113. Ausbürgerungsliste, A-K). Dort wird der 3o. September 1933 als Auswanderungsdatum angezeigt, was aufgrund der im Sommer 1933 in der Schweiz komponierten Lieder kaum stimmen kann.

Aufgrund der Recherchen in Amsterdamer Archiven kommen Philip Silver und Carine Alders zum Schluss, dass Anna Simon-Levy (wohl unmittelbar nach der Haftentlassung wegen Devisenvergehen) nach Amsterdam flüchtete, wohin ihr Mann nachreiste. Sie lebten dort getrennt, ohne die Ehe offiziell aufzulösen. Später gelang es Anna SimonLevy, in die Schweiz zu flüchten. Simons jüngster Sohn setzte sich nach London ab. James Simon fand in Amsterdam als Klavierlehrer, Komponist und Pianist ein ziemlich erfolgreiches Auskommen.

30 Auch für diesen Hinweis danke ich Walter Labhart.

31 Zu berücksichtigen ist dabei, dass die jüdische Herkunft seines Namens wegen des berühmten jüdischen Mäzens und Unternehmers James Simon (1851-1932), nach dem heute in Berlin der James-Simon-Park und die James-Simon-Galerie auf der Museumsinsel benannt sind, sofort erkannt wurde.

32 Straschek: [Unterlagen zu James Simon].

33 Ritter: TonFilmführer, S. 340. 
die Mutter Nachkommen d. Komp. Meyerbeer. Vater = Bankier Martin Simon, Mutter = Rosa Steinthal. $\ll^{34}$

In der von Wilhelm Altmann betreuten 14. Ausgabe (1936) von Kurzgefaßtes Tonkünstler-Lexikon wird die Tarnung offengelegt: »ps. Peter POTTER; soll seit 1935 in Amsterdam (1934 in Zürich) leben « ${ }^{35}$ Im 1940 erschienenen Lexikon der Juden in der Musik von Theo Stengel und Herbert Gerigk bekommt Simon wie alle anderen bloß noch einen sehr kurzen Eintrag: »Simon, Dr. James (Ps. Potter, Peter), * Berlin 29.9.188o, Pian, Komp. ML - Berlin. «36 Musikalische Leistungen werden in diesem Lexikon keine mehr genannt; es geht nur noch darum, eine Verfolgungsliste für die Gestapo auszustellen.

Am 3o. Mai 1939 wurde vom SS-Hauptsturmführer Walter Jagusch (19102007) die »Aberkennung der deutschen Staatsangehörigkeit « beantragt: ${ }^{37}$

Der Komponist James Simon ist Jude und besitzt die deutsche Staatsangehörigkeit. Er ist am 30.9.1933 von Berlin nach London ausgewandert.

Simon war marxistisch eingestellt und unterhielt Verbindungen zu marxistischen Kreisen des In- und Auslandes. Seine Ehefrau Anna geb. Levy, geb. am 17.2.85 zu Berlin, ist im Jahre 1933 wegen Devisenvergehens mit 3 Monaten Gefängnis und RM 5000.-- Geldstrafe bestraft worden. ${ }^{38}$ Aus der Ehe sind die Kinder

a) Ulrich Simon, geb. am 21.9.13 zu Berlin-Grunewald, und

b) Jörn Simon, geb. am 14.9.10 zu Berlin,

hervorgegangen. Der Sohn Jörn betätigte sich bereits im Sommer 1931 für eine neugegründete Spieltruppe »Kulturbolschewisten", die in einem Rundschreiben angab, dass sie sich gegen den Hochschulfaschismus und für eine Stärkung der roten Einheitsfront einsetzen wollen. Wenn auch der Sohn Ulrich bisher in politischer und krimineller Hinsicht nicht in Erscheinung getreten ist, muss doch angenommen werden, dass er infolge der Erziehung die staatsfeindliche Einstellung seiner Eltern und seines Bruders teilt. Die Voraussetzungen für die Aberkennung der Staatsangehörigkeit sind damit gegeben.

34 Rock/Brückner:Judentum und Musik, S. 210.

35 Frank/Altmann: Kurzgefaßtes Tonkünstler-Lexikon (1936), S. $5^{83}$.

36 Stengel/Gerigk: Lexikon der Juden in der Musik, S. $25^{8}$.

37 Politisches Archiv des Auswärtigen Amtes Berlin: Archivband R 99804 (Referat Deutschland, 113. Ausbürgerungsliste, A-K). Alle kursiv gesetzten Stellen sind im Original mit Bleistift unterstrichen. Alle Informationen und Zitate zu den Söhnen von Simon stammen ebenfalls aus dieser Akte.

38 Diese Gefängnisstrafe von Anna Simon-Levy wegen Devisenvergehens - was auf Eintausch von Edelmetallen hinweist und von den Nationalsozialisten später mit dem Tod bestraft wurde - dürfte der Grund sein, weshalb die aktenkundige Auswanderung der Familie Simon erst im Herbst 1933 erfolgte. Es ist also möglich, dass Simon im April 1933 in die Schweiz floh, um den Verhaftungswellen von Kommunisten zu entkommen und vielleicht auch Vermögenswerte in Sicherheit zu bringen. 
Ich bitte, das Weitere zu veranlassen und die Ausbürgerung auf die Ehefrau sowie die Kinder zu erstrecken.

Vermögenswerte hat die Familie Simon im Inlande nicht hinterlassen.

Ferner bitte ich, hinsichtlich der Entziehung der Dr.-Würde des James Simon gleichfalls das Erforderliche zu veranlassen. Er hat am 17.1.1905 vor der philosophischen Fakultät der Universität München zum Dr. phil. promoviert.

Dem Auswärtigen Amt und der für den Wohnsitz des Auszubürgernden zuständigen deutschen Vertretung im Auslande habe ich je eine Durchschrift dieses Schreibens übersandt.

Dass es zu dieser Ausbürgerung kam, lag wohl zu einem großen Teil daran, dass James Simon Erkundigungen veranlasst hatte, um den seit Herbst 1937 in Moskau verschollenen Sohn zu finden. Er wandte sich nicht nur an das polnische Rote Kreuz, sondern auch an das Auswärtige Amt Berlin mit der Bitte, Nachforschungen zu betreiben. Tatsächlich verfasste die zuständige Behörde diesbezügich einen Bericht. Dessen Zustellung wurde allerdings lange hinausgezögert, da gegen James Simon eine Passsperre vorlag, welche die Aushändigung der Informationen verhinderte. Erst am 6. Oktober 1938 bekam Simon von der deutschen Botschaft in Moskau einen Bescheid, der bestätigte, dass sein Sohn nicht auffindbar sei; die Nachricht mündet im Fazit:

»Aus der Lage der Verhältnisse muss angenommen werden, dass Ihr Sohn im Zuge der gegen alle Ausländer in der Sowjet-Union durchgeführten Polizeiaktion im Herbst vorigen Jahres verhaftet worden ist.«

Vom auf Polnisch verfassten Brief des polnischen Roten Kreuzes vom 21. September 1938 hatte Simon zudem erfahren, dass Jörn Martin Simon wahrscheinlich im berüchtigten Butyrka-Gefängnis unter Spionage-Verdacht inhaftiert war. Aufgrund der Akten, die im deutschen Bundesinnenministerium einsehbar sind, hat James Simon einen heute nicht mehr erhaltenen, ausführlichen Fragebogen ausgefüllt, um weitere Nachforschungen in Moskau zu erreichen. Mit all diesen Aktivitäten lenkte er die Aufmerksamkeit auf seine eigene Person. Er wurde nun selbst ins Visier genommen, denn die deutsche Botschaft in Moskau fragt am 3o. Januar 1939 im Auswärtigen Amt nach, ob die Gestapo ihre »Stellungnahme über die Person des nebenbezeichneten Reichsangehörigen dem Auswärtigen Amt inzwischen mitgeteilt hat und die Botschaft sich weiter mit dem Fall befassen soll.« Das nächste Dokument in der Akte Simon ist der Order von Walter Jagusch zum Entzug der Staatsangehörigkeit und der Aberkennung der Doktorwürde.

Im Zeitraum dieser Nachforschungen zum Verbleib seines Sohnes in der UdSSR reiste Simon 1938 nach Tel Aviv, um seine Schwester Bertha Seligsohn (1882-1938) zu besuchen. Bei seiner Ankunft in Palästina vernahm er, dass sie 
verstorben war. ${ }^{39}$ In Erinnerung an ihren Tod komponierte er ein Lamento im jemenitischen Stil. Erhielt an der UniversitätJerusalem ein Referat in deutscher Sprache zur Musik in der Bibel. Seine nach Palästina ausgewanderten Eltern und sein Schwager versuchten ihn zum Bleiben in Tel Aviv zu überreden, aber James Simon schätzte seine Situation in Amsterdam als sicher ein und konnte sich nicht vorstellen, in einem Land zu leben, in dem Deutsch nicht verstanden wurde. Ähnlich reagierte er auf entsprechende Einladungen von Toni Appelbaum, in die USA auszuwandern. Selbst als seine Eltern ihm nach dem Einmarsch der Wehrmacht telegrafierten, sofort unterzutauchen, war er immer noch der Überzeugung, dass man im Ausland den Ernst der Lage überbewertete. Andere nach Amsterdam geflüchtete Juden übernahmen die gleiche Haltung, etwa der Arzt und Musikwissenschaftler Kurt Singer (18851944), der ehemalige Vorsitzender des jüdischen Kulturbundes. Er schrieb in Amsterdam eine umfassende Studie zu einem christlichen Kernrepertoire, nämlich Johann Sebastian Bachs Solo-Kantaten, die er James Simon zur Kritik unterbreitete. Dieser schreibt Singer am 23. September 1940 eine ausführliche Kritik, die launig-ironisch umrahmt ist:

Nie kann man sagen, was man sagen müsste (Michelangelo über Dante) - und doch haben mir Ihre von umfassender Kenntnis und glühender Begeisterung diktierten Betrachtungen über Bach und seine Kantaten sehr sehr viel gegeben. Sie bieten über ermittelte Tatbestände hinaus manches Neue und Beherzigenswerte, wie etwa mit der Parallele Bach-Leibniz. Und ich war dankbar, das Gottesreich einmal unter Ihrer Führung betreten zu dürfen! - Hier folgen nun ein paar Randbemerkungen, zunächst zu den Solokantaten.

Und dann folgt eine detaillierte Auflistung von Singers Übertreibungen und Fehleinschätzungen. Simon greift dabei auch auf die Bach-Ausgaben von Busoni und Reger zurück und beendet den vierseitigen Brief mit einem versöhnlichen Schluss, der auch die Anspielung auf Michelangelo erklärt:

Mit der Versicherung, dass ich nie aufhören werde, im Buch vom Wirken des Weltgesetzes, im musikalischen Tao te king, zu lesen, und auf Wiedersehen morgen Michelangelostr.! So beginnt und endet diese Epistel mit Michelangelo wie die Musik mit Bach. ${ }^{40}$

39 Vgl. Silver/Alders: James Simon.

40 Simon: Brief vom 23.09.1940. Singers unpublizierte Studie Johann Sebastian Bachs Kantatenwelt. Die Solo-Kantaten hat in verschiedenen Varianten in den Nachlässen der Sängerinnen Vera Consuelo Hirsch (nach Buenos Aires emigriert) und Paula SalomonLindberg (aus dem Lager Westerbork geflohen und in Amsterdam untergetaucht) 
Als Simon diesen Brief schrieb, war Amsterdam schon seit mehr als vier Monaten besetzt. Die falsche Sicherheit, in der sich James Simon in Amsterdam wähnte, lag auch am relativen Erfolg, den er als Musiker immer noch erfahren durfte. So bekam Simon die Zusage, dass das ConcertgebouwOrchester seine Symphonischen Tänze spielen würde; aber da nach der deutschen Besetzung 1940 sämtliche Werke jüdischer Komponisten von den Programmen gestrichen wurden, kam es nicht zur Aufführung. Trotzdem konnte er als Pianist im Radio auftreten und Scarlatti, Martini, Haydn, Mozart und Beethoven spielen. Noch am 26. Januar 1941 organisiert die Nederlandsche Vereeniging voor Hedendaagsche Muziek (Niederländische Gesellschaft für zeitgenössische Musik) ein Konzert zum 6o. Geburtstag, einen Monat vor dem berühmten Amsterdamer Februarstreik gegen die nationalsozialistischen Besatzer. Am 24. August 1941 gab er mit der Geigerin Alma Rosé, der Nichte von Gustav Mahler und Tochter von Robert Rosé, dem Primgeiger des berühmten Rosé-Quartetts, ein Konzert im Het Apeldoornsche Bosch, einer jüdischen psychiatrischen Klinik, denn öffentliche Auftritte jüdischer Musiker waren da schon verboten. Auf dem Programm standen neben Beethovens Frühlingssonate auch Klavierstücke von Mendelssohn und die Grosse Fantasie D 934 von Schubert. Alma Rosé und James Simon wurden später Opfer des Holocaust. Rosé versuchte von Amsterdam in die Schweiz zu fliehen, wurde aber von der Gestapo in Frankreich verhaftet und nach Auschwitz transportiert, wo sie am 2O. Juli 1943 eintraf und bald danach das sogenannte >Mädchenorchester< leitete. Am 5. April 1944 starb sie unter ungeklärten Umständen an einer unbekannten Krankheit. James Simon konnte sich in Amsterdam noch bis 1944 durchschlagen, wurde aber im Frühjahr 1944 verhaftet und ins holländische Lager Westerbork gebracht. Am 4. April 1944 wurde er von Westerbork zusammen mit Tausenden von Juden nach Theresienstadt transportiert. Dort integrierte er sich sofort ins Musikleben des Lagers, komponierte zum Beispiel für Karel Fischers Durra-Chor den 126. Psalm, der am 9. Juli 1944 uraufgeführt und später noch sechsmal wiederholt wurde. Neben Referaten zu deutschen Komponisten hielt Simon auch in Theresienstadt einen Vortrag zur Musik in der Bibel, den er mit seiner heute verschollenen Vertonung von Psalm 137 einleitete, in dem die Gefangenen von ihren Peinigern zum Singen und Jubeln gezwungen werden.

überlebt (Akademie der Künste Berlin: Singer 1.55.053.1-4; Singer 1.55.039; Singer 1.55.oo1; Singer 1.55.0031.55). Kurt Singer wurde 1943 in Amsterdam verhaftet und nach Theresienstadt deportiert, wo er am 7. Februar 1944 an den Folgen der Haftbedingungen starb. 
Dem Mithäftling Karl Herrmann, der in Theresienstadt die Ankündigungen für Theater- und Musikveranstaltungen und andere Dokumente sammelte und im Gebälk versteckte, widmete er ein Blatt, auf dem er das arabische Sprichwort »Tu Gutes und wirf es in Meer« notierte.

Am 12. Oktober 1944 wurde Simon von Theresienstadt ins Vernichtungslager Auschwitz deportiert und dort gleich nach der Ankunft am 14. Oktober ermordet.

\subsection{Die Walser-Vertonungen im Kontext von Simons Liederzyklen}

$5^{1}$ gedruckte Lieder und Gesänge von James Simon sind in der Staatsbibliothek Berlin erhalten. Sie datieren alle vor den Umwälzungen, die Simons Biografie ab Mitte der 1920er-Jahren prägen und die ihn auch literarisch zu neuen Ufern aufbrechen lassen. Die von ihm zuvor vertonten Dichter bilden eine kleine Anthologie der deutschen Lyrik mit Goethe als ältestem und Klabund als jüngstem deutschen Schriftsteller. Aber auch der chinesische Dichter Li Bai (8. Jahrhundert) findet sich darunter. Zwei Volkslieder und Texte von insgesamt 38 Dichtern hat er in den 51 Liedern vertont, Simon hat also einen Autor meist bloß ein einziges Mal in Musik gesetzt. Mehrfach vertont werden nur Otto Julius Bierbaum (2), Max Dauthendey (7), Li Bai/Bethge (3), Conrad Ferdinand Meyer (2) und Robert Walser (2). Die Auswahl an Dichtern belegt Simons große literarische Bildung, die er sich schon während seiner Studien bei den führenden Germanisten Deutschlands angeeignet hatte. Fast alle namhaften Lyriker des 19. und 20. Jahrhunderts werden von ihm vertont. Interessant ist, welche älteren Autoren Simon nicht berücksichtigt, nämlich Heinrich Heine, Joseph von Eichendorff und Friedrich Hölderlin. Die Gründe dafür dürften unterschiedlich sein: Heine und von Eichendorff mied Simon wohl, weil sie schon so zahlreich und von den besten Liederkomponisten vertont worden waren; Hölderlin umgekehrt wurde damals gerade erst entdeckt und war noch nicht in den lyrischen Kanon integriert und erst von ganz wenigen vertont worden.

Die verschiedenen Lieder ordnete Simon jeweils in Zyklen an, die in sich thematische Einheiten bilden und mit tonartlichen Spannungen und stilistischen Wechseln den Werkcharakter des Zyklus akzentuieren. Die beiden Zyklen Opus 6 und Opus 17, in denen Gedichte aus Walsers 1909 im Berliner Verlag Cassirer erschienenen Gedichten vertont sind, zeigen diesen zyklischen Gedanken deutlich. 


\subsubsection{Opus 6 für mittlere Stimme und Klavier}

Die Lieder op. 6 umfassen fünf Abend- und Nachtgedichte von sehr unterschiedlichen Autoren, davon zwei Schweizer. Zwei waren Zeitgenossen von Simon und drei stammen aus dem 19. Jahrhundert. In fast allen Zyklen von Simon finden sich auch heute vergessene Autoren, wie hier der Literat und frühe Hölderlinforscher Hans Wolfgang Rath:

1. Gebet von Robert Walser. Ruhig mit innigem Ausdruck, Es-Dur.

2. Dämmerung von Hans Wolfgang Rath. Zart beschwingt, f-Moll.

3. Jetzt rede du! von Conrad Ferdinand Meyer. Etwas langsam, A-Dur.

4. Das sind die Stunden von Rainer Maria Rilke. Ruhig fliessend, Des-Dur.

5. Die Weihe der Nacht von Friedrich Hebbel. Weihevoll, Ges-Dur.

Das erste und das letzte Lied bilden eine Klammer und sind durch die religiöse Anspielung aufeinander bezogen, allerdings in unterschiedlicher Perspektive: Bei Walser beschränkt sich das Religiöse auf den Titel Gebet, im Gedicht selbst steht die Erschöpfung und Sehnsucht nach Ruhe als Reaktion auf den »hingewachten « Tag im Zentrum; Hebbels Weihe der Nacht versteht die »nächtliche Stille« als Erholung und Wandlung. ${ }^{41}$ Das zweite und vierte Gedicht schildern die Natur, leicht und unbeschwert bei der Dämmerung, ernst und zur »einigende[n] Harmonie «42 gesteigert bei Rilke. Das mittlere Lied von Conrad Ferdinand Meyer steht mit A-Dur am weitesten von der Anfangstonart Es-Dur entfernt und bildet tonartlich in diesem Zyklus, der sonst nur B-Tonarten verwendet, einen wechseldominantischen Gegenpol.

Wenn man Simons Vertonung gerecht werden will, muss man akzeptieren, dass er in einem konservativen Stil komponierte, der sich von seinen Zeitgenossen Mahler, Schönberg oder Reger deutlich unterscheidet. Seine Harmonik geht über Felix Mendelssohn und Robert Schumann kaum hinaus. Wer allerdings dieser Musik mit offenem Ohr lauscht und bereit ist, Differenzierungen auch in einem traditionellen harmonischen Material herauszuhören, begegnet einem äußerst sensiblen Komponisten, der die vertonten Texte genau versteht und sie musikalisch subtil nachvollzieht; er akzentuiert das Besondere des Gedichtes und hält sich mit eigenen Interpretationen zurück (vgl. Abb. 1).

41 Hebbel: Die Weihe der Nacht, S. 285f.

42 Rilke: Werke, Bd. 1, S. 104. 
Aufführungsrecht vorbehalten.

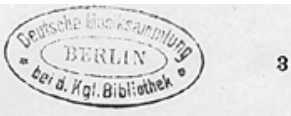

Gebet.

(Robert.Walser)

James Simon, 0p. 6.
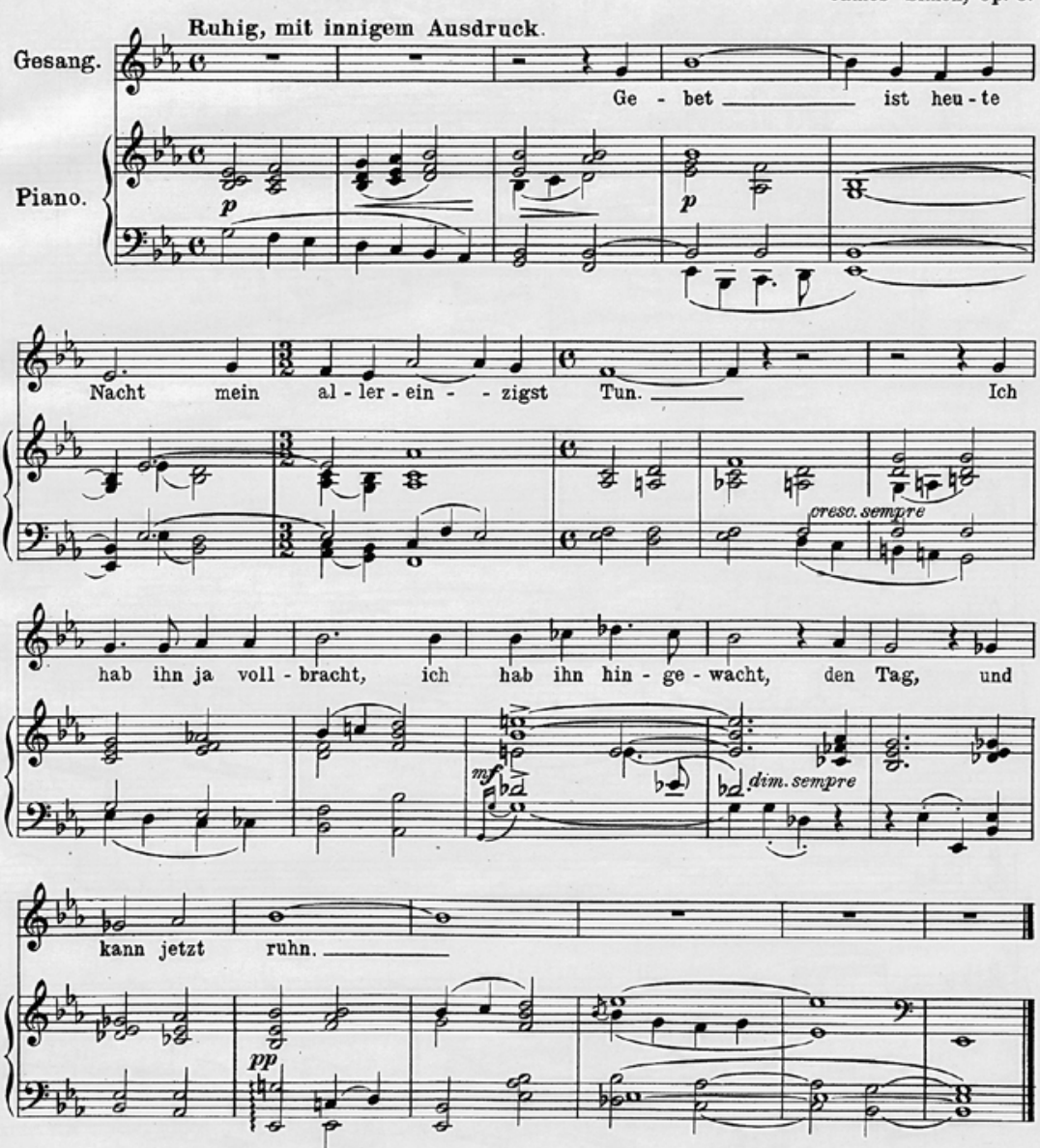

Copyright 1912 by N. Simrook, G.m.b. H., Berlin.

12984

Abb. 1 James Simon: Gebet op. 6 Nr. 1 


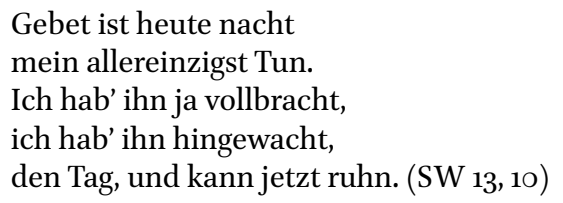

Das ganze Lied ist als ruhig fließender Choral gestaltet, was mit der abwärts schreitenden Basslinie bis zum tiefen Es im instrumentalen Vorspiel ostentativ vorgeführt wird. Die Bewegungen der linken und rechten Hand streben auseinander, auch steigt die Harmonik in barocker Manier stufenweise hoch, während die Basslinie absinkt. Anfänglich ist die Harmonik trotz ihrer Einfachheit tonartlich offen; Es-Dur wird als Tonart erst im dritten Takt klar bestätigt. Die Harmonik verwendet bis zu Takt 8 nur leitereigene Töne, dabei dominieren Dreiklänge, was dem Beginn einen archaischen und energielosen Charakter gibt, der die erschöpft-melancholische Atmosphäre des Gedichts sehr gut trifft. Der Umfang der Singstimme ist extrem eingeschränkt und bewegt sich ausschließlich im Septimraum $e s^{1}$ bis $d e s^{2}$, auch dies eine Anspielung an den Choral. Mit diesem beschränkten Material arbeitet Simon die Spannungen des Gedichts heraus: Der höchste Ton der Singstimme wird nur ein einziges Mal beim auffälligen Wort »hingewacht«, der tiefste nur zweimal bei »Nacht« und »allereinzigst « verwendet. Die Tonhöhen $g^{1}$ und $b^{1}$ sind quasi die Achsentöne, sie kommen zusammen 13-mal vor, also deutlich mehr als alle anderen Tonhöhen gemeinsam. Und mit dem $b^{1}$ werden auch die Versenden (»vollbracht «, »hingewacht «, »ruh«) gestaltet, allerdings jedesmal in einer anderen harmonischen Variante: bei »vollbracht« als Grundton des B-Dur-Akkords, bei »hingewacht« als verminderter Quintton des verminderten Septakkords auf E und bei »ruhn« als Quintton des Es-Dur-Akkords. In genau dieser Funktion tritt $b^{1}$ auch zu Beginn bei Gebet auf. So werden Anfang und Schluss des Gedichts von Simon musikalisch zusammengefasst und das Gebet als Ruhepunkt interpretiert. Interessant ist, wie das erste $g^{1}$ der Singstimme stark dissonierend zum $a s^{1}$ und $F$ in der Klavierbegleitung eintritt und in die Harmonik des Dominantseptakkords nicht eingebunden ist. Die Töne $g^{1}$ und $b^{1}$ sind wahrscheinlich so exklusiv verwendet - und auch als Anfangstöne der Melodie gewählt -, weil die Tonnamen phonetisch das GeBet nachbilden.

Auch im deklamatorisch-rhythmischen Bereich bleibt Simon nahe bei der Vorlage: Sowohl die unregelmäßige Rhythmik der ersten und letzten Verszeile mit »Gebet« und »den Tag« als auch der Reim »Tun« - »ruhn« sind mit langgehaltenen Tönen nachvollzogen. 
Die Harmonik setzt Simon stärker interpretierend ein: So bleibt bei »allereinzigst Tun « die Harmonik auf dem f-Moll-Septakkord und fällt dann auf dem lange gehaltenen $f^{1}$ der Singstimme in eine harmonische Wechselbewegung mit einem d-Moll-Dreiklang, der mit dem $a$ die leitereigenen Töne von Es-Dur erstmals verlässt - ein minimaler >Ausbruch< aus dem System, während die mediantische Harmonik von f-Moll und d-Moll eine träumerischunbestimmte Stimmung evoziert, die allerdings mit dem Dominantseptakkord auf $G$ in Takt 10 klar unterbrochen und trugschlüssig über c-Moll zum »vollbracht« auf der zu erwartenden Dominante von Es-Dur führt. Die vierte Verszeile, die bei Walser wie eine Sequenz der dritten erscheint, wird von Simon harmonisch unterschiedlich vertont, um das »hingewacht « nicht nur mit dem höchsten Melodieton, sondern mit dem über anderthalb Takte gezogenen verminderten Septakkord auch harmonisch und zusätzlich mit dem Arpeggio des Klaviers hervorzuheben. Auch hier dissoniert das $c e s^{2}$ der Singstimme scharf mit dem ohnehin dissonanten Septakkord. Schon die zahlreichen Vorzeichen markieren den harmonisch dominantischen chromatischen $»$ Tag «. Abrupt verdunkelt sich bei »den Tag« die Harmonik; sie kippt in den subdominantischen Neapolitaner und führt über as-Moll zum Es-Dur bei »ruhn«. Damit findet die Chromatik, die bei Simon stark mit dem »Tag « verbunden ist, ein Ende; nur in Takt 19 erklingt nochmals kurz ein leiterfremder Ton.

Das tiefe $E s$, der letzte vom Klavier angeschlagene Ton, hebt die wichtigen Wörter hervor: »[Ge]bet «, »Nacht«, »Tag «, »ruhn« «sind mit diesem Es gestützt; beim Wort »Gebet« wird dieses Es von der Basslinie ein einziges Mal noch unterschritten, sonst bildet das Es den unteren Klangrand.

Die hier verwendeten musikalischen Mittel sind 1912 schon hundert Jahre alt und wenig innovativ, die Umsetzung von Walsers Text ist jedoch präzise und mit viel Gefühl für dessen schlichten Ton gestaltet.

\subsubsection{Opus 17}

Noch nirgends erwähnt ist bisher die zweite Vertonung James Simons eines Gedichts von Robert Walser. Es handelt sich um das letzte aus dem Band Gedichte von 1909 und befindet sich in einem literarisch etwas weniger anspruchsvollen Zyklus mit stark genremäßig angelegten Gedichten. ${ }^{43}$ Walsers Text bildet in diesem Zyklus die Mitte. Ihm voraus gehen ein freudiges Sommergedicht von Bierbaum und ein etwas pathetischer Text von Girndt zur Heimatlosigkeit und zur sie überwindenden Liebe; auf Walsers Gelassenheit folgen ein romantisches Mondgedicht von Falke und ein Wiegenlied von Enking. 
1. Singe, meine liebe Seele von Otto Julius Bierbaum. Froh bewegt, Des-Dur.

2. Ich habe keine Heimat mehr von Otto Girndt. Im Volkston. Gehend, herzlich, F-Dur.

3. Gelassenheit von Robert Walser. In mäßiger Bewegung, D-Dur.

4. Rosen von Gustav Falke. Nicht schnell, duftig, Ges-Dur

5. Schlummerlied von Ottomar Enking. In sachter Bewegung, zart, E-Dur

Unter den fünf Liedern sticht die Walser-Vertonung durch viele Tonartwechsel und leise Ironie hervor (vgl. Abb. 2):

Seit ich mich der Zeit ergeben, fühl' ich etwas in mir leben, warme, wundervolle Ruh'.

Seit ich scherze unumwunden mit den Tagen, mit den Stunden, schließen meine Klagen zu.

Und ich bin der Bürd' entladen, meiner Schulden, die mir schaden, durch ein unverblümtes Wort: Zeit ist Zeit, sie mag entschlafen, immer findet sie als braven Menschen mich am alten Ort. (SW 13, 28f.)

Wie schon bei Gebet wählt Simon eine Dur-Tonart, die Walsers Gedicht aufhellt, ihm eine positive Note verleiht und in der rhythmisch einfachen und melodisch anfänglich fast volksliedhaften Melodik das unbeschwerte Reden Walsers gut einfängt. Noch stärker als bei Gebet, das im Genre des Chorals verhaftet bleibt, gelingt es Simon bei Gelassenheit, das Uneigentliche, die Zwischentöne, das >Patzige< von Walser kompositorisch umzusetzen. Dabei spielt er wie seine Vorbilder Schubert und Schumann mit den interpretatorischen Nuancen, die das variierte Strophenlied bietet, da in diesem alle Abweichungen bedeutungsvoll werden. Sehr schön lässt sich das an der Art zeigen, wie Simon die lose gefügten und überraschenden Reime von Walser umsetzt. Der erste Dreizeiler bildet das konventionelle Modell, bei dem jeder Reim abkadenziert wird. Beim zweiten Dreizeiler der ersten Strophe werden die ersten beiden Reime in der Vertonung nicht berücksichtigt: »unumwunden« ist in eine Achtelbewegung integriert, »Stunden« übernimmt die fallende Klausel von »Tagen«. Beides ist deklamatorisch sinnvoll, beim Schluss des zweiten Dreizeilers geht Simon allerdings zum Modell zurück und wiederholt die Schlussklausel des ersten Dreizeilers, mit der auffälligen Bindung von zwei Tönen auf einer Silbe. Diese Schleifer fallen umso mehr auf, als sie nur gerade bei »wundervolle« und »Klagen« sowie als verspielt-ironische Achtelfiguren auf 
8

Auffuhrungsrecht vorbehalten.

\section{Gelassenheit.}

\section{(Robert Walser.)}

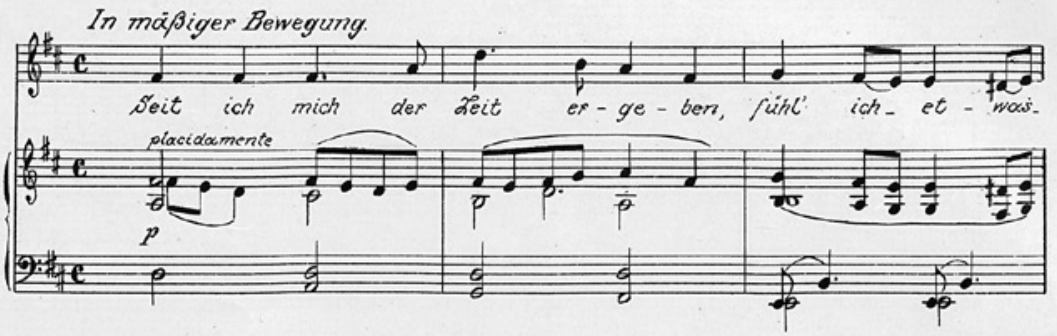

James Simon, Op. 17 № 3.
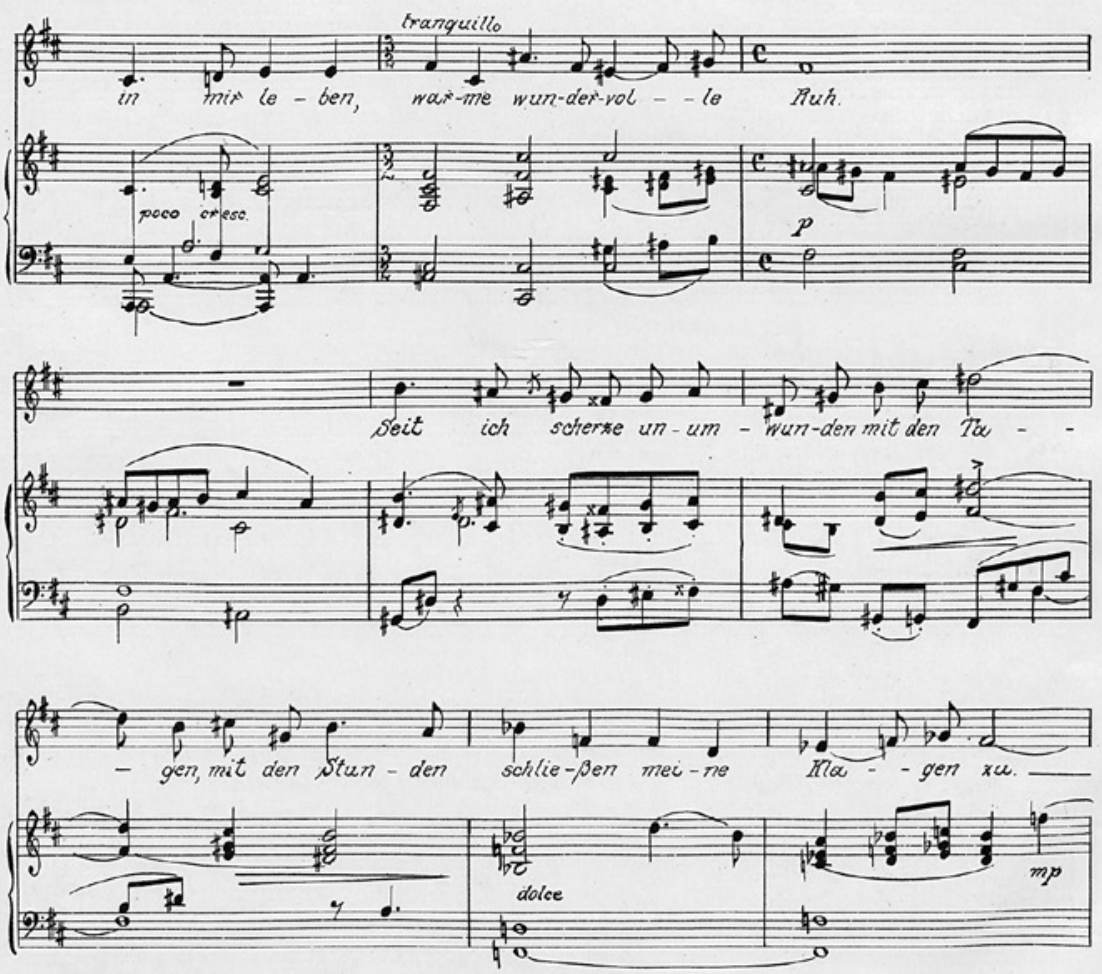

Copyright 1915 by Harmonie-Verlag, Berlin w.
Nachdruck verboten it. dem russischen Autorenge

und nach dem hollindisechen Autorengesetz vongesetz vom 20. Mtïn 1911

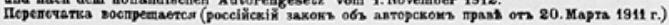

Abb. 2 James Simon: Gelassenheit op. 17 Nr. 3 

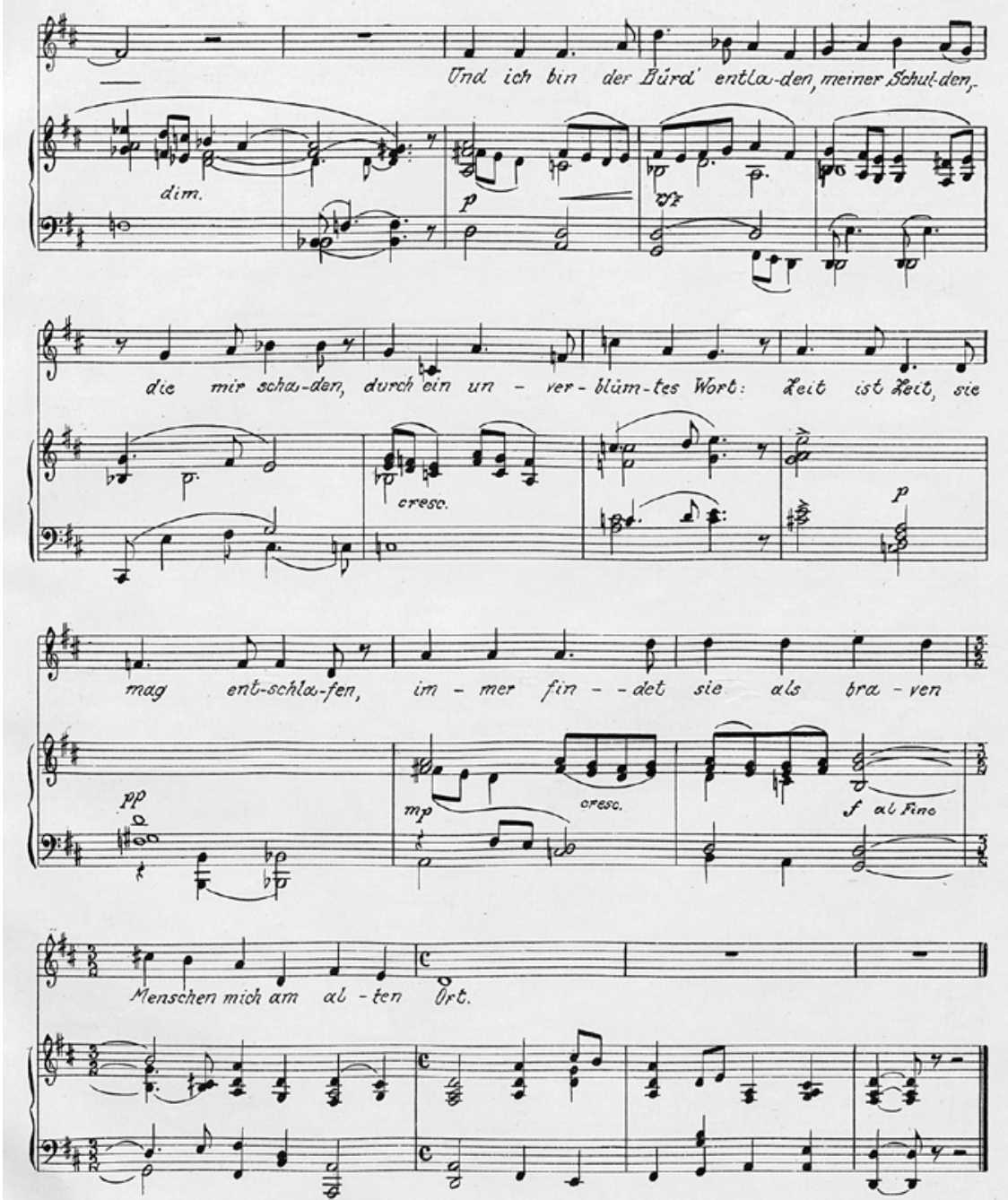
den unbetonten zweiten Silben von »etwas« und »Schulden« vorkommen. Mit der identischen Gestaltung der Klauseln wird Simon zwar den Regeln des variierten Strophenlieds gerecht, er verstärkt damit aber auch Walsers >ächzenden Reim mit »wundervolle Ruh« und »meine Klagen zu«. Die zweite Strophe wird von Simon mit einem synkopischen Einsatz bei »die mir schaden« deklamatorisch noch reicher gestaltet, die Wirkung ist aber dieselbe: Walsers Gedicht soll doppelbödig und ironisch erscheinen, nicht als eigentliches Singen und Sprechen missverstanden werden. Dazu hilft auch die Harmonik, die nur gerade in den ersten und letzten vier Takten und zu Beginn der zweiten Strophe (bei Takt 15) sich klar in D-Dur befindet. Schon die zweite Verszeile »fühlte etwas in mir leben« moduliert nach e-Moll, die dritte »warme wundervolle Ruh« nach Fis-Dur. Bei »seit ich scherze« geht es nach gis-Moll und bei »mit den Stunden « nach H-Dur, dann abrupt bei den »Klagen« nach B-Dur. Mit diesen Tonartwechseln - die zweite Strophe ist vergleichbar gestaltet - will Simon wohl das Übermütige und das in alle Richtungen Herumfantasierende von Walser einfangen. Dabei gibt es auch selbstreferentielle Aspekte, etwa wenn er Walsers nichtssagende Formel »Zeit ist Zeit« seinerseits mit einem musikalischen Klischee, nämlich der QuintfallFormel (mit zwei Dominantseptakkorden) umsetzt, oder noch deutlicher am Ende des Liedes, wo die Rückkehr »als braven Menschen « »am alten Ort« mit der Rückkehr nach D-Dur und einem an Konventionalität schwer zu überbietenden Schluss parallelisiert wird.

\section{$1.8 \quad$ Epilog}

Leider konnten keine Belege dafür gefunden werden, dass Walser und Simon sich in Berlin begegnet sind. Bei den wenigen nachweisbaren Bekanntschaften von Simon gibt es keine Überschneidungen zum relativ großen Berliner Bekanntenkreis der Walser-Brüder. Dennoch ist es wahrscheinlich, dass Walser und Simon mindestens auf den Seiten der Feuilletons aufeindergetroffen sind, für die sie geschrieben und die sie gelesen haben.

Die Schicksale, die sich bei diesen ersten Walser-Vertonungen in Berlin kreuzen, können einen jedenfalls erschauern lassen: Der Komponist schlägt sich durch die politischen Wirren in Berlin und wird Opfer des Holocaust, der Dichter kehrt 1913 in die Schweiz zurück und endet in der Herisauer Nervenklinik. 